\title{
Effect of temperature on pyrolysis of sewage sludge: biochar properties and environmental risks from heavy metals
}

\author{
Zhipu Wang ${ }^{1,3}$, Shun $\mathrm{Liu}^{1}$, Kai $\mathrm{Liu}^{2}{ }^{* *}$, Shibo $\mathrm{Ji}^{3}$, Mingming Wang ${ }^{4}$, and Xinqian $\mathrm{Shu}^{3}$ \\ ${ }^{1}$ State Key Laboratory of Heavy Oil Processing, China University of Petroleum-Beijing at Karamay, 834000 Karamay, China \\ ${ }^{2}$ School of Municipal and Environmental Engineering, Henan University of Urban Construction, 467036 Pingdingshan, China \\ ${ }^{3}$ School of Chemical and Environmental Engineering, China University of Mining \& Technology (Beijing), 100083 Beijing, China \\ ${ }^{4}$ PetroChina Xinjiang Oilfield Company, 834000 Karamay, China
}

\begin{abstract}
Biochars were prepared via the pyrolysis of sewage sludge at temperatures ranging from $350-550{ }^{\circ} \mathrm{C}$. The properties and behaviors of heavy metals in the biochars were investigated. The results indicated that the $\mathrm{pH}$ values and ash contents of the biochars increased, while biochar yield and $\mathrm{C}, \mathrm{H}$, and $\mathrm{N}$ contents decreased with the increasing temperature. A high pyrolysis temperature contributed to a developed biochar pore structure. The specific surface area and pore volume of the biochars increased, while the average pore width decreased, with the increasing temperature. Heavy metals in the biochars were further enriched with the increasing temperature. TCLP tests demonstrated that the leaching potential of heavy metals from the biochars significantly decreased with the increasing temperature, indicating the decrease of potential ecological risks of heavy metals to the environment. Additionally, BCR tests confirmed the transformation of heavy metals from mobile fractions (F1 and F2) to stable fractions (F3 and F4). The evaluation results showed that a high pyrolysis temperature can effectively inhibit the ecological risks of heavy metals in the biochars. Thus, the conversion of sewage sludge into biochar via pyrolysis is a promising method for the safe disposal of sewage sludge.
\end{abstract}

\section{Introduction}

Sewage sludge is a by-product of municipal wastewater treatment plants. With continuous urbanization worldwide, many municipal sewage treatment plants have been constructed, and the amount of discharged sewage sludge is increasing dramatically. Sewage sludge contains a large amount of heavy metals and pathogenic microbes that can cause serious environmental pollution and even threaten human health once directly discharged into the environment [1]. The proper disposal of sewage sludge has attracted great interest, and the organic composition in sewage sludge is also considered as an important biological resource. Therefore, it is necessary to develop appropriate disposal technology to both reuse resources and safely dispose of sewage sludge.

Pyrolysis may provide a feasible and attractive strategy for sludge recycling [2], since it can reduce sludge volume, kill pathogens and parasites [3], and convert the organic matter in sewage sludge into bio-oil, pyrolysis gas, and biochar [4]. Sludge-derived biochar is a kind of porous material with an abundance of nutrients including $\mathrm{N}, \mathrm{P}$, and $\mathrm{K}$ [5]. It is also a potential amendment to contaminated soil, and its application to soils may decrease soil bulk density [6], increase soil porosity [7], enhance soil water holding capacity [8-10], increase soil nutrient retention capacity [10], adsorb soil pollutants [11], improve the nutrient supply for plants [12], and enhance plant growth [13].

The characteristics of sludge-derived biochars have an important influence on their improvement to degraded soils. Detailed research is required on the elemental compositions, physicochemical properties, and pore structures of sludge-derived biochars. Moreover, sludge-derived biochars are enriched in heavy metals [14], and the behaviors of those heavy metals require further research to minimize the risks of their release into the environment. Pyrolysis temperature is the key factor that determines the characteristics of biochar [15-16]. Therefore, the aims of this study are (1) to investigate the effect of pyrolysis temperature on the properties of sludge-derived biochar, (2) to explore the effects of pyrolysis temperature on the transformations of heavy metals during the pyrolysis process, and (3) to reduce the potential ecological risks of heavy metals in biochar.

\section{Materials and methods}

*Corresponding author mail: wzpcumt@163.com

**Corresponding author mail: liukaicumtb@163.com 


\subsection{Pyrolysis feedstocks}

The sewage sludge used in this study was collected from the sludge dehydrating unit of a municipal wastewater treatment plant in Urumqi, Xinjiang Province, China, and was air dried outdoors. The sludge was dried to constant weight at $85{ }^{\circ} \mathrm{C}$ in a laboratory oven, ground through a 60 -mesh sieve, and packed in sealed plastic bags for further use. The sludge is labeled as SS. The properties of the sludge are listed in Table 1.

\subsection{Pyrolysis experiments}

The pyrolysis experiments were conducted at a pyrolysis temperature ranging from 350 to $550{ }^{\circ} \mathrm{C}$ [17] and a heating rate of $20^{\circ} \mathrm{C} / \mathrm{min}$ in an electric heating furnace. Figure 1 presents a schematic diagram of the furnace consisting of a nitrogen conveyor, a pyrolysis reactor, and a liquid separator.

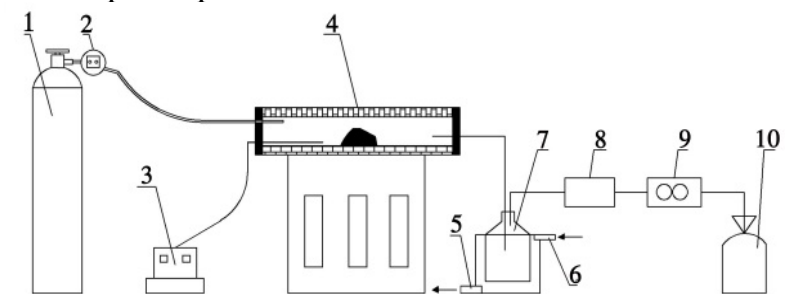

1. nitrogen gas, 2. pressure gage, 3. temperature controller, 4. electrical heating furnace, 5 . water outlet tube, 6 . water inlet tube, 7. water bath, 8. desiccator, 9. active carbon filter, 10. gas collector.

Fig. 1. Schematic diagram of the pyrolysis furnace.
Before and during the pyrolysis process, a continuous inflow of $\mathrm{N}_{2}$ at $0.5 \mathrm{~L} / \mathrm{min}$ was sent to the furnace to achieve an oxygen-free environment. A total of $30 \mathrm{~g}$ of dry SS was placed in the quartz tube, fed into the middle portion of the furnace, and heated for $2 \mathrm{~h}$ after reaching the target temperature. The solid products (biochars) were cooled to room temperature and weighed, and the biochar yield was determined according to equation (1). The biochar prepared by the pyrolysis of the sludge at $\mathrm{X}$ $\left({ }^{\circ} \mathrm{C}\right)$ was labeled as SSBX.

$$
Y_{b}=\frac{M_{b}}{M_{s}}
$$

where $Y_{b}$ represents the yield of the biochar, and $M_{b}$ and $M_{s}$ represent the dry weights of the biochar and sludge, respectively.

\subsection{Characterization of the sludge and biochars}

The $\mathrm{C}, \mathrm{H}$, and $\mathrm{N}$ contents of the sludge and biochars were determined simultaneously by using an elemental analyzer (Flash, Ea11121, USA). The pH values of the samples (sample/water, 1:20, w/v) were measured with a digital $\mathrm{pH}$ meter (PHS-3C, China). The BET (Brunauer-Emmett-Teller) surface area, pore volume, and pore size of the samples were determined with an automated surface area and pore size analyzer (ASAP2020; Micrometrics, USA). The ash contents of the samples were measured according to the methods listed in the standard procedures of the Chinese standard GB/T212-2008 [18].

Table 1. General properties of the sludge and biochars.

\begin{tabular}{|c|c|c|c|c|c|c|c|}
\hline \multirow{2}{*}{ Samples } & \multirow{2}{*}{ Yield (\%) } & \multirow{2}{*}{$\mathrm{pH}$} & \multicolumn{3}{|c|}{ Element contents $(\%)$} & \multirow{2}{*}{$\mathrm{H} / \mathrm{C}$} & \multirow{2}{*}{$\operatorname{Ash}^{\mathrm{b}}(\%)$} \\
\hline & & & $\mathrm{C}$ & $\mathrm{H}$ & $\mathrm{N}$ & & \\
\hline SS & $-{ }^{\mathrm{a}}$ & $7.03 \pm 0.05$ & 26.15 & 3.86 & 4.57 & 0.15 & $46.66 \pm 2.15$ \\
\hline SSB350 & $73.33 \pm 1.20$ & $7.42 \pm 0.03$ & 25.32 & 2.16 & 3.15 & 0.09 & $55.14 \pm 2.39$ \\
\hline SSB450 & $67.13 \pm 1.13$ & $8.07 \pm 0.02$ & 24.28 & 1.71 & 2.98 & 0.07 & $64.36 \pm 3.11$ \\
\hline SSB550 & $61.28 \pm 0.92$ & $8.54 \pm 0.03$ & 19.89 & 1.09 & 2.35 & 0.05 & $72.42 \pm 2.84$ \\
\hline
\end{tabular}

${ }^{\mathrm{a}}$ Not determined.

${ }^{\mathrm{b}}$ On a dried base.

\subsection{Analytical methods for heavy metals}

Before the total contents of heavy metals in the sludge and biochars were tested, these samples were first digested according to Wang et al [19]. The BCR (the European Community Bureau of Reference) sequential extraction method was used to analyze the chemical form distributions of heavy metals in the samples [20]. The TCLP (toxicity characteristic leaching procedure) was used to analyze the leachable toxicities of heavy metals in the samples [21]. The concentrations of heavy metals in the solutions were determined by using inductively coupled plasma optical emission spectrometry (ICP-OES, Optima5300, Perkin Elmer, USA). The ecological risks of heavy metals in the sludge and biochars were assessed according to Wang et al [19].

\subsection{Statistical analyses}

Statistical analyses were performed by using the SPSS statistical package (v. 19.0, IBM Corp., Armonk, NY, USA). The data were subjected to variance analysis. The means were separated by using the protected least significant difference test at $p<0.05$.

\section{Results and Discussions}

\subsection{General Properties}

The general properties of the samples (the sludge and biochars) are listed in Table 1. The biochar yield decreased from $73.33 \%$ to $61.28 \%$ with the increase of pyrolysis temperature from 350 to $550{ }^{\circ} \mathrm{C}$. Moreover, compared with the sludge, the contents of $\mathrm{C}, \mathrm{H}$, and $\mathrm{N}$ of biochar SSB350 obviously decreased after pyrolysis at $350{ }^{\circ} \mathrm{C}$. The decomposition of organic matter into volatile substances during the pyrolysis process was the 
reason for these decreases [22]. Furthermore, the contents of these elements gradually decreased with the increase of pyrolysis temperature, indicating the increased thermal decomposition of organic matter at higher temperatures. These results were consistent with the research of Jin et al [23]. The $\mathrm{H} / \mathrm{C}$ atomic ratio of the biochars obviously decreased with the increase of temperature, indicating that an elevated temperature can increase the aromatization degree of biochar [20], [24-25].

The ash content of biochar was positively correlated with pyrolysis temperature. When the pyrolysis temperature increased from 350 to $550{ }^{\circ} \mathrm{C}$, the ash content of the biochar increased from $55.14 \%$ to $72.42 \%$. In this study, higher pyrolysis temperatures resulted in higher alkalinity of the biochar. There were two main mechanisms to explain this phenomenon. First, more alkali salts were released from the organic structure at higher temperatures. Second, more organic amines were converted to pyridines with the increase of pyrolysis temperature, resulting in the decrease of acid functional groups on the biochar surface.

\subsection{Characterization of the biochars}

The pore structure characteristics of the sludge and biochars are exhibited in Table 2 . The results suggest that pyrolysis of the sludge at higher temperatures promoted the development of the pore structures of biochars. When the temperature increased from 350 to $550{ }^{\circ} \mathrm{C}$, the specific surface area and total pore volume of the biochars increased from $8.01 \mathrm{~m}^{2} / \mathrm{g}$ and $0.041 \mathrm{~cm}^{3} / \mathrm{g}$ to $10.23 \mathrm{~m}^{2} / \mathrm{g}$ and $0.062 \mathrm{~cm}^{3} / \mathrm{g}$, respectively, while the average pore size decreased from $23.50 \mathrm{~nm}$ to $16.40 \mathrm{~nm}$. The volatilization of organic matter in biochar is helpful to the development of pore structure [20].

Table 2. Pore structures of the sludge and biochars.

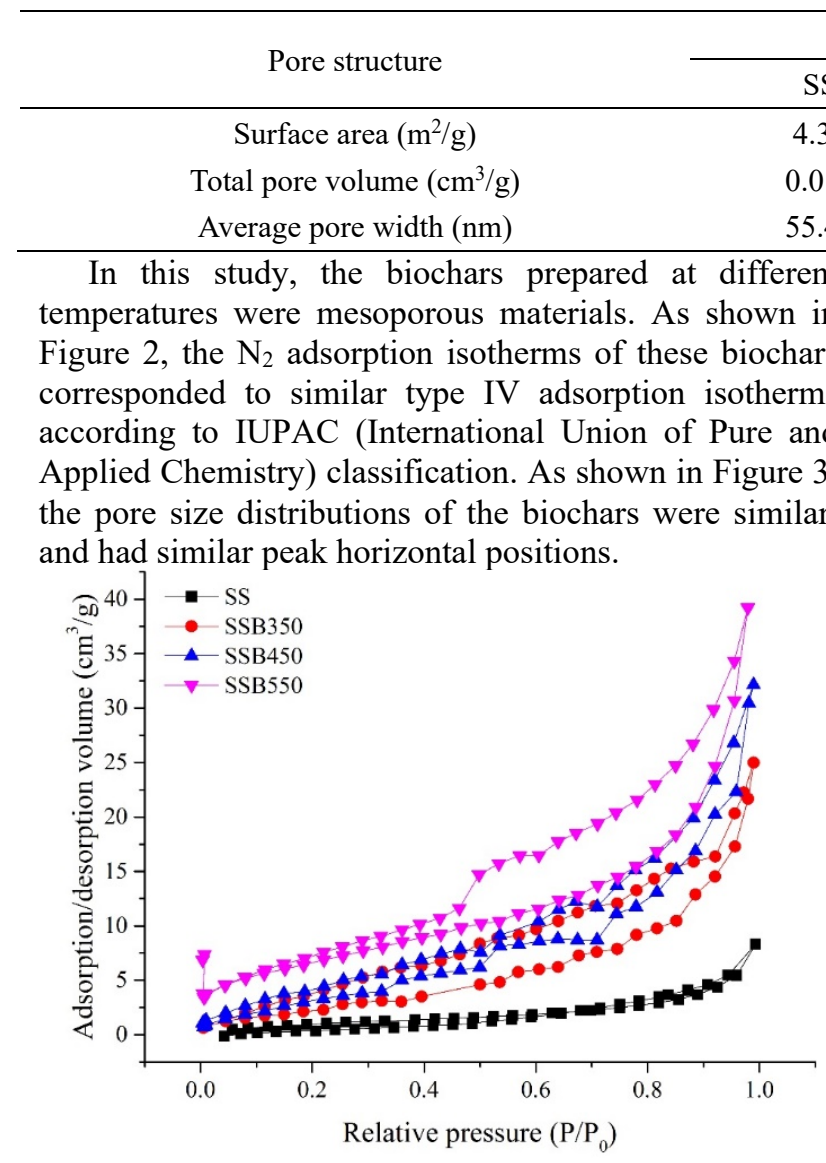

Fig. 2. Nitrogen adsorption-desorption isotherms of biochars obtained at different pyrolysis temperatures. 
pyrolysis temperatures caused the enrichment of heavy metals in the biochars.

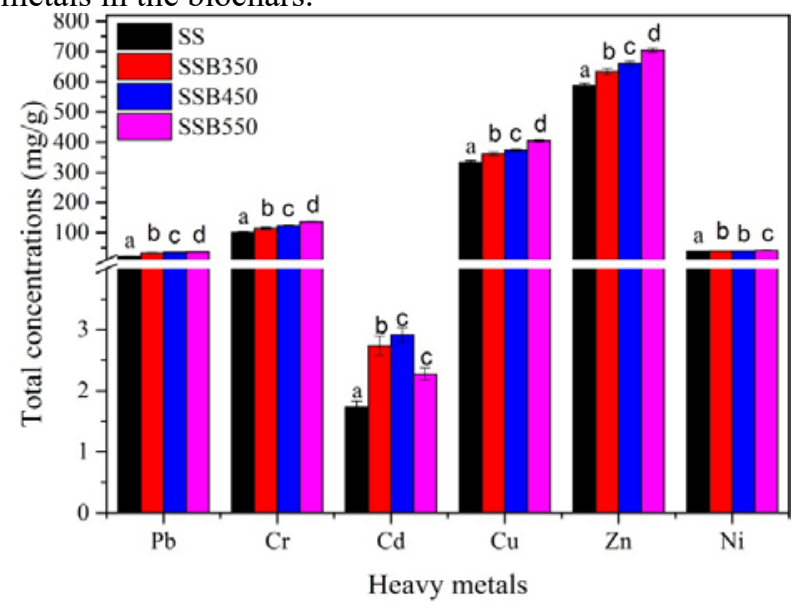

Fig. 4. Total concentrations of heavy metals in the sludge and biochars.

\subsubsection{Concentrations of BCR-extractable fractions}

The BCR (European Community Bureau of Reference) method is always used to quantitatively analyze the chemical form distributions of heavy metals in sediment, soil, and biochars $[4,26]$. According to the BCR method, heavy metals are classified into four chemical forms: (1) acid soluble/exchangeable fraction $(\mathrm{F} 1),(2)$ reducible fraction (F2), (3) oxidizable fraction (F3), and (4) residual fraction (F4), including residual and silicate-bound heavy metals [27]. The chemical form distributions of the six heavy metals in the sludge and biochars are presented in Figure 5.
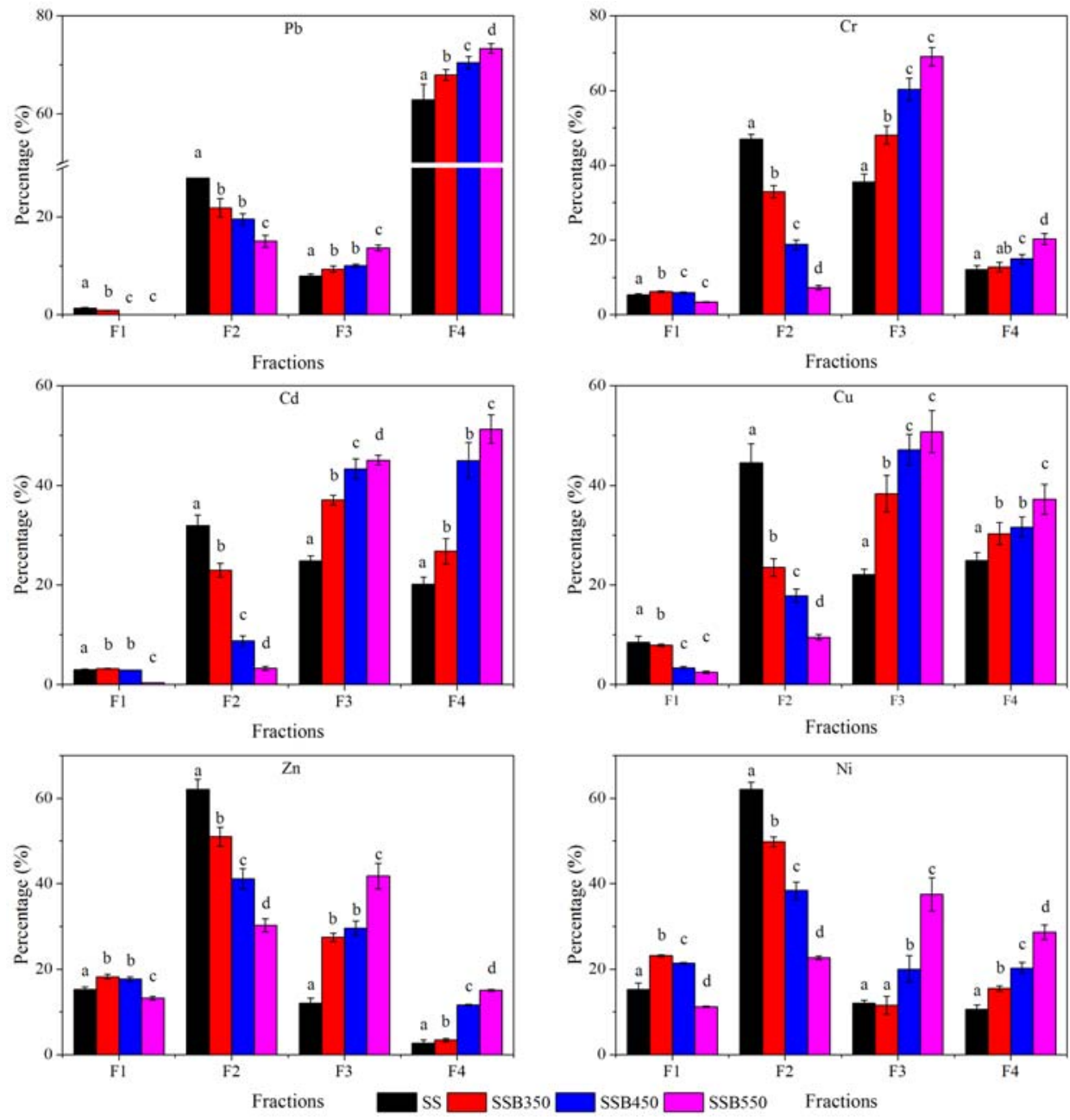

Fig. 5. Chemical form distributions of heavy metals in the sludge and biochars.

For $\mathrm{Pb}$, the percentages of $\mathrm{F} 1, \mathrm{~F} 2, \mathrm{~F} 3$, and F4 in the sludge were $1.36 \%, 27.90 \%, 7.92 \%$, and $62.82 \%$, respectively. Compared with the sludge, the percentages of $\mathrm{Pb}$ in F1 and F2 in biochar SSB350 decreased, while those in F3 and F4 obviously increased. Furthermore, when the temperature increased from $350{ }^{\circ} \mathrm{C}$ to $550{ }^{\circ} \mathrm{C}$, the percentage of $\mathrm{Pb}$ in $\mathrm{F} 1$ decreased from $0.90 \%$ to $0 \%$, and that in F2 decreased from $27.90 \%$ to $21.88 \%$. In contrast, the percentages of $\mathrm{Pb}$ in F3 and F4 increased from $7.92 \%$ to $9.31 \%$ and $62.82 \%$ to $67.91 \%$, 
respectively. These results suggest that pyrolysis at a high temperature effectively promoted the transformation of $\mathrm{Pb}$ from $\mathrm{F} 1$ and $\mathrm{F} 2$ to $\mathrm{F} 3$ and F4. Meanwhile, the increase of temperature had similar effects on the chemical form distributions of the other five heavy metals $(\mathrm{Cd}, \mathrm{Cu}, \mathrm{Cr}, \mathrm{Zn}$, and $\mathrm{Ni}$ ).

During the pyrolysis process, organic compounds in the sludge were decomposed into phenols, acids, and aromatic compounds, and heavy metals combined with organic functional groups, such as hydroxyl groups, to form stable coordination compounds [28]. Moreover, some metals combined with $\mathrm{Si}-\mathrm{O}$ bonds [26]. These factors caused the transformations of those heavy metals from F1 and F2 to F3 to F4. Previous research has confirmed that metals presenting in $\mathrm{F} 3$ and $\mathrm{F} 4$ are more stable in the environment than those in F1 and F2 [29]. Therefore, pyrolysis can effectively stabilize heavy metals in sludge and reduce the possibility of their release into the environment.

Table 3. Leaching toxicities of the heavy metals from the sludge and biochars.

\begin{tabular}{ccccccc}
\hline \multirow{2}{*}{ Samples } & \multicolumn{5}{c}{ Heavy metals $(\mathrm{mg} / \mathrm{g})$} \\
\cline { 2 - 7 } & $\mathrm{Pb}$ & $\mathrm{Cr}$ & $\mathrm{Cd}$ & $\mathrm{Cu}$ & $\mathrm{Zn}$ & $\mathrm{Ni}$ \\
\hline SS & $0.53\left(2.55^{\mathrm{a}}\right)$ & $3.21(3.20)$ & $0.16(9.34)$ & $30.80(9.22)$ & $34.99(5.96)$ & $1.34(3.53)$ \\
SSB350 & $0.31(1.21)$ & $1.73(1.52)$ & $0.14(4.78)$ & $20.13(5.56)$ & $22.83(2.34)$ & $0.51(1.75)$ \\
SSB450 & $0.29(1.07)$ & $1.50(1.22)$ & $0.13(4.44)$ & $12.11(3.24)$ & $22.19(2.18)$ & $0.46(1.28)$ \\
SSB550 & $0.25(0.83)$ & $1.05(0.78)$ & $0.10(3.27)$ & $10.65(2.63)$ & $15.07(1.39)$ & $0.43(1.03)$ \\
Standard $^{\mathrm{b}}$ & 5.0 & 5.0 & 1.0 & Not enlisted & Not enlisted & 5.0
\end{tabular}

${ }^{a}$ Leaching rate (\%): the ratio of the leaching content of heavy metals to the total concentration of each heavy metal.

bUSEPA test methods for evaluating solid waste; physical/chemical methods of total concentration of each heavy metal (SW-846) (Huang \& Yuan, 2016).

\subsubsection{Leachable toxicity of heavy metals}

The leaching characteristics of the heavy metals in the sludge and biochars are exhibited in Table 3. In this study, the leaching contents of all six heavy metals from the sludge and biochars were below the permissible limits [18]. Compared with the sludge, the leaching contents of the six heavy metals in biochar SSB350 decreased significantly, and the increase in temperature further reduced the leaching contents of these heavy metals. For $\mathrm{Pb}$, the leaching content decreased from 0.31 $\mathrm{mg} / \mathrm{g}$ to $0.25 \mathrm{mg} / \mathrm{g}$, and the leaching rate decreased from $1.21 \%$ to $0.83 \%$. The leaching characteristics of the other five heavy metals exhibited similar trends. Thus, pyrolysis at a high temperature had a noticeable effect on the alleviation of the leaching toxicities of the six heavy metals in the sludge. This observation was in accordance with that obtained by Jin et al [23].

\subsubsection{Ecological risk assessment of heavy metals}

The ecological risk index (GRI) is always used to evaluate the ecological risks of single and multiple metals in water, sediment, soil, and biochars [18], [20].
In this study, this method was used to assess the ecological risks of heavy metals in the sludge and biochars prepared at different pyrolysis temperatures, and the values were computed by using the following formulas:

$$
\begin{aligned}
& I C F=\frac{C_{F 1+F 2+F 3}}{C_{F 4}} \\
& G C F=\sum_{i=1}^{n} I C F_{i} \\
& G R I=\sum_{i=1}^{n} \operatorname{Tr}^{i} I C F_{i}
\end{aligned}
$$

where $C_{F 1+F 2+F 3}$ is the sum of the total concentrations of a single heavy metal presenting in fractions $\mathrm{F} 1+\mathrm{F} 2+$ $\mathrm{F} 3, C_{F 4}$ is the total concentration of a single heavy metal in fraction $\mathrm{F} 4$, and $T r^{i}$ is the toxic response factor, which is the response factor for the ecological toxicity of a single heavy metal [30]. Furthermore, ICF and GCF are the contamination factors of a single heavy metal and multi-metals, respectively. GRI represents the ecological risks of heavy metals $(\mathrm{Pb}, \mathrm{Zn}, \mathrm{Cd}, \mathrm{Cr}, \mathrm{Cu}$, and $\mathrm{Ni})$ in the samples. The ICF, GCF, and GRI values of the samples

\begin{tabular}{|c|c|c|c|c|c|c|c|c|}
\hline \multirow{2}{*}{ Samples } & \multicolumn{6}{|c|}{$\mathrm{ICF}^{\mathrm{a}}$} & \multirow{2}{*}{$\mathrm{GCF}^{\mathrm{b}}$} & \multirow{2}{*}{$\mathrm{GRI}^{\mathrm{c}}$} \\
\hline & $\mathrm{Pb}$ & $\mathrm{Cr}$ & $\mathrm{Cd}$ & $\mathrm{Cu}$ & $\mathrm{Zn}$ & $\mathrm{Ni}$ & & \\
\hline SS & 0.59 & 7.28 & 1.49 & 3.02 & 8.49 & 8.43 & 29.20 & 137.43 \\
\hline SSB350 & 0.47 & 6.84 & 2.36 & 2.30 & 6.47 & 5.45 & 23.89 & 137.25 \\
\hline SSB450 & 0.42 & 5.68 & 1.22 & 2.16 & 7.62 & 3.95 & 21.05 & 94.20 \\
\hline SSB550 & 0.39 & 3.94 & 0.95 & 1.69 & 5.66 & 2.49 & 15.12 & 69.13 \\
\hline
\end{tabular}
are listed in Table 4.

Table 4. Assessment of ecological risks of heavy metals in the sludge and biochars.

${ }^{\mathrm{a}} I C F: \leq 1,1-3,3-6$, and $>6$ denote low, moderate, considerable, and high contamination risks, respectively. 
${ }^{\mathrm{b}} G C F$ : $<6,6-12,12-24$, and $>24$ denote low, moderate, considerable, and high contamination risks, respectively.

${ }^{\mathrm{C}} G R I:<150,150-300,300-600$, and $>600$ denote low, moderate, considerable, and high ecological risks, respectively.

The assessment results reveal that the ICF value of $\mathrm{Zn}$ was the highest of the six heavy metals for both the sludge and the biochars. The GCF value of the sludge was 29.20 . After pyrolysis at $350{ }^{\circ} \mathrm{C}$, the GCF value of the biochar SCB350 decreased to 23.89. Moreover, the GCF values of the biochars obviously decreased with the increase of pyrolysis temperature (Table 4). In the GRI analysis, the GRI values of the sludge and SSB350 were 137.43 and 137.25 , respectively, which are both at the low risk level. Additionally, the GRI values of the biochars decreased with the increase of pyrolysis temperature. These results suggest that the evaluated pyrolysis temperatures effectively reduced the ecological risks of both single and multiple heavy metals in the biochars.

This can be explained as follows. During the pyrolysis process, metals presenting in mobile fractions F1 and F2 were released from the organic structure of the sludge and transferred into stable fractions F3 and F4, resulting in the decrease of ecological risks of those heavy metals. Furthermore, the increase of pyrolysis temperature enhanced this process, as shown in Figure 5.

\section{Conclusions}

With the increase of pyrolysis temperature, the biochar yield decreased obviously, but the $\mathrm{pH}$ value and ash content increased. Additionally, the increase of pyrolysis temperature reduced the $\mathrm{H} / \mathrm{C}$ ratio of the biochar, increased its specific surface area and total pore volume, and reduced its pore size. the total concentration of heavy metals in the biochars further increased with the increase of pyrolysis temperature. Elevated pyrolysis temperatures effectively inhibited the leaching potential of heavy metals from the biochars, contributed to the transformation of heavy metals from mobile fractions (F1 and F2) to stable ones (F3 and F4), and effectively reduced the potential ecological risks of heavy metals in the biochars. These results suggest that biochar prepared via the pyrolysis of sewage sludge at a high temperature is more suitable for soil improvement. However, the effects of pyrolysis residence time and heating rate on the characteristics of sewage sludge-derived biochar require further investigation.

\section{Acknowledgements}

This work was supported by the Science and Technology Foundation of Karamay (No. 2020CXRC0013), Joint Foundation of China University of Petroleum-Beijing at Karamay (No. XQZX20200014), and the Natural Science Foundation of China (No. 51074170).

\section{References}

1. Y. Zhou, Y. Liu, W. Jiang, L. Shao, L. Zhang, L. Feng, Effects of pyrolysis temperature and addition proportions of corncob on the distribution of products and potential energy recovery during the preparation of sludge activated carbon, Chemosphere 221, 175-183 (2019).

2. Shao, W. Jiang, L. Feng, L. Zhang, Co-production of activated carbon, fuel-gas, and oil from the pyrolysis of corncob mixtures with wet and dried sewage sludge, Waste Manag Res 32, 519-526 (2014).

3. Z. Li, H. Deng, L. Yang, G. Zhang, Y. Li, Y. Ren, Influence of potassium hydroxide activation on characteristics and environmental risk of heavy metals in chars derived from municipal sewage sludge, Bioresour Technol 256, 216-223 (2018).

4. X. Wang, Q. Chi, X. Liu, Y. Wang, Influence of pyrolysis temperature on characteristics and environmental risk of heavy metals in pyrolyzed biochar made from hydrothermally treated sewage sludge, Chemosphere 216, 698-706 (2019).

5. K. Wang, Y. Zheng, X. Zhu, C.E. Brewer, R.C. Brown, Ex-situ catalytic pyrolysis of wastewater sewage sludge - A micro-pyrolysis study, Bioresour Technol 232, 229-234 (2017).

6. W. Buss, M.C. Graham, J.G. Shepherd, O. Mašek, Suitability of marginal biomass-derived biochars for soil amendment, Sci Total Environ 547, 314-322 (2016).

7. S. Van Wesenbeeck, W. Prins, F. Ronsse, M.J. Antal, Sewage Sludge Carbonization for Biochar Applications. Fate of Heavy Metals, Energy \& Fuels 28, 5318-5326 (2014).

8. S. Bruun, S.L. Harmer, G. Bekiaris, W. Christel, L. Zuin, Y. Hu, L.S. Jensen, E. Lombi, The effect of different pyrolysis temperatures on the speciation and availability in soil of $\mathrm{P}$ in biochar produced from the solid fraction of manure, Chemosphere 169, 377-386 (2017).

9. A. Méndez, A.M. Tarquis, A. Saa-Requejo, F. Guerrero, G. Gascó, Influence of pyrolysis temperature on composted sewage sludge biochar priming effect in a loamy soil, Chemosphere 93, 668-676 (2013).

10. Y. Yue, L. Cui, Q. Lin, G. Li, X. Zhao, Efficiency of sewage sludge biochar in improving urban soil properties and promoting grass growth, Chemosphere 173, 551-556 (2017).

11. D. Zhou, D. Liu, F. Gao, M. Li, X. Luo, Effects of Biochar-Derived Sewage Sludge on Heavy Metal Adsorption and Immobilization in Soils, Int $\mathrm{J}$ Environ Res Public Health 14, 7 (2017).

12. H. Yuan, T. Lu, Y. Wang, Y. Chen, T. Lei, Sewage sludge biochar: Nutrient composition and its effect on the leaching of soil nutrients, Geoderma 267, 17-23 (2016).

13. M.K. Hossain, V. Strezov, P.F. Nelson, Comparative Assessment of the Effect of Wastewater Sludge Biochar on Growth, Yield and Metal 
Bioaccumulation of Cherry Tomato, Pedosphere 25, 680-685 (2015).

14. Z. Khanmohammadi, M. Afyuni, M.R. Mosaddeghi, Effect of pyrolysis temperature on chemical and physical properties of sewage sludge biochar, Waste Manag Res 33, 275-283 (2015).

15. H. Chen, Y. Zhai, B. Xu, B. Xiang, L. Zhu, L. Qiu, X. Liu, C. Li, G. Zeng, Characterization of bio-oil and biochar from high-temperature pyrolysis of sewage sludge, Environ Technol 36, 470-478 (2015).

16. L.J. Leng, X.Z. Yuan, H.J. Huang, H. Wang, Z.B. Wu, L.H. Fu, X. Peng, X.H. Chen, G.M. Zeng, Characterization and application of bio-chars from liquefaction of microalgae, lignocellulosic biomass and sewage sludge, Fuel Processing Technology 129, 8-14 (2015).

17. X.D. Song, X.Y. Xue, D.Z. Chen, P.J. He, X.H. Dai, Application of biochar from sewage sludge to plant cultivation: Influence of pyrolysis temperature and biochar-to-soil ratio on yield and heavy metal accumulation, Chemosphere 109, 213-220 (2014).

18. H.J. Huang, X.Z. Yuan, The migration and transformation behaviors of heavy metals during the hydrothermal treatment of sewage sludge, Bioresour Technol 200, 991-998 (2016).

19. Z. Wang, J. Wang, L. Xie, H. Zhu, X. Shu, Influence of the Addition of Cotton Stalk during Co-pyrolysis with Sewage Sludge on the Properties, Surface Characteristics, and Ecological Risks of Biochars, J. Therm. Sci. 15, 551-556 (2019).

20. J. Jin, M. Wang, Y. Cao, S. Wu, P. Liang, Y. Li, J. Zhang, J. Zhang, M.H. Wong, S. Shan, P. Christie, Cumulative effects of bamboo sawdust addition on pyrolysis of sewage sludge: Biochar properties and environmental risk from metals, Bioresour Technol 228, 218-226 (2017).

21. Z. Wang, X. Shu, H. Zhu, L. Xie, S. Cheng, Y. Zhang, Characteristics of biochars prepared by co-pyrolysis of sewage sludge and cotton stalk intended for use as soil amendments, Environ. Technol. 41, 1347-1357 (2020).

22. S. Wei, M. Zhu, X. Fan, J. Song, P.a. Peng, K. Li, W. Jia, H. Song, Influence of pyrolysis temperature and feedstock on carbon fractions of biochar produced from pyrolysis of rice straw, pine wood, pig manure and sewage sludge, Chemosphere 218, 624-631
(2019).

23. J. Jin, Y. Li, J. Zhang, S. Wu, Y. Cao, P. Liang, J. Zhang, M.H. Wong, M. Wang, S. Shan, P. Christie, Influence of pyrolysis temperature on properties and environmental safety of heavy metals in biochars derived from municipal sewage sludge, J Hazard Mater 320, 417-426 (2016).

24. M.I. Al-Wabel, A. Al-Omran, A.H. El-Naggar, M. Nadeem, A.R. Usman, Pyrolysis temperature induced changes in characteristics and chemical composition of biochar produced from conocarpus wastes, Bioresour Technol 131， 374-379 (2013).

25. Y.K. Choi, E. Kan, Effects of pyrolysis temperature on the physicochemical properties of alfalfa-derived biochar for the adsorption of bisphenol $A$ and sulfamethoxazole in water, Chemosphere 218, 741-748 (2019).

26. B. Zhao, X. Xu, S. Xu, X. Chen, H. Li, F. Zeng, Surface characteristics and potential ecological risk evaluation of heavy metals in the bio-char produced by co-pyrolysis from municipal sewage sludge and hazelnut shell with zinc chloride, Bioresour Technol 243, 375-383 (2017).

27. B.S. Sagagi, C.M. Davidson, A.S. Hursthouse, Adaptation of the BCR sequential extraction procedure for fractionation of potentially toxic elements in airborne particulate matter collected during routine air quality monitoring, Int. J. Environ. Anal. Chem. 10, 1-13 (2019).

28. N. Gao, C. Quan, B. Liu, Z. Li, C. Wu, A. Li, Continuous Pyrolysis of Sewage Sludge in a Screw-Feeding Reactor: Products Characterization and Ecological Risk Assessment of Heavy Metals, Energy \& Fuels. 31, 5063-5072 (2017).

29. G. Rauret, Extraction procedures for the determination of heavy metals in contaminated soil and sediment, Talanta 46, 449-455 (1998).

30. P. Devi, A.K. Saroha, Risk analysis of pyrolyzed biochar made from paper mill effluent treatment plant sludge for bioavailability and eco-toxicity of heavy metals, Bioresour Technol 162, 308-315 (2014). 